\title{
Como os turistas provenientes de países do Corredor Bioceânico "enxergam" os atrativos turísticos de Bonito, MS: uma análise calcada em princípios da netnografia
}

\author{
How tourists from countries of the Bioceanic Highroad Crossing "see" the \\ tourist attractions of Bonito, MS, Brazil: an analysis based on netnography \\ principles
}

\section{Como los turistas provenientes de países de la Ruta Bioceánica "dan cuenta" de los atractivos turísticos de Bonito, MS, Brasil: un análisis calcado en principios de la netnografía}

\author{
Maurílio Barbosa de Oliveira da Silva ${ }^{1}$ \\ Maria Clara de Souza Moreira ${ }^{1}$ \\ Dyego de Oliveira Arruda ${ }^{2}$ \\ Milton Augusto Pasquotto Mariani ${ }^{1}$
}

Recebido em 01/11/2018; revisado e aprovado em 18/01/2019; aceito em 02/06/2019

DOI: http://dx.doi.org/10.20435/inter.v20iespecial.2211

\begin{abstract}
Resumo: Este estudo objetiva compreender como os turistas do Paraguai, Argentina e Chile "enxergam" os atributos dos atrativos turísticos de Bonito, MS, um importante destino turístico na área de influência do Corredor Bioceânico. Para tanto, realizou-se uma pesquisa netnográfica, com o uso do software Iramuteq. Verificou-se que os turistas valorizam os atributos relacionados ao meio ambiente, corroborando a ênfase de Bonito, MS em atividades ligadas ao ecoturismo.
\end{abstract}

Palavras-chave: Corredor Bioceânico; turismo; Bonito/MS; netnografia; Iramuteq.

Abstract: This study aims to understand how tourists from Paraguay, Argentina and Chile "see" the attributes of the tourist attractions of Bonito, MS, Brazil, an important tourist destination in the influence area of the Bioceanic Highroad Crossing. Therefore, a netnographic research was carried out, using the Iramuteq software. It was verified that the tourists value the attributes related to the environment, corroborating the emphasis of Bonito, MS in activities related to ecotourism.

Keywords: Bioceanic Route; tourism; Bonito/MS/Brazil; netnography; Iramuteq.

Resumen: Este estudio pretende comprender cómo los turistas de Paraguay, Argentina y Chile "dan cuenta" de los atributos de los atractivos turísticos de Bonito, MS, Brasil, un importante destino turístico en el área de influencia de la Ruta Bioceánica. Para esto, se realizó una investigación netnográfica, con el uso del software Iramuteq. Se verificó que los turistas valoran los atributos relacionados al medio ambiente, corroborando el énfasis de Bonito, MS en actividades ligadas al ecoturismo.

Palabras clave: Ruta Bioceánica; turismo; Bonito/MS/Brasil; netnografía; Iramuteq.

\section{INTRODUÇÃO}

O fenômeno contemporâneo da globalização, que implica na transposição de fronteiras geográficas de países e/ou territórios para a realização de intercâmbios culturais, de pessoas e de produtos (bens e serviços), tende a estimular os processos de criação de blocos de integração socioeconômica e cultural - tais como a União Europeia (UE), o Tratado Norte-Americano de Livre Comércio (NAFTA), além do Mercado Comum do Sul (Mercosul), só para citar alguns poucos exemplos (D'ONOFRIO; ROUSSEAU, 2018).

\footnotetext{
${ }^{1}$ Universidade Federal de Mato Grosso do Sul (UFMS), Campo Grande, Mato Grosso do Sul, Brasil.

${ }^{2}$ Universidade Federal de Mato Grosso do Sul (UFMS), Campo Grande, Mato Grosso do Sul, Brasil; Centro Federal de Educação Tecnológica Celso Suckow da Fonseca (CEFET/RJ), Valença, Rio de Janeiro, Brasil
} 
Parte-se da perspectiva de que a integração sociocultural e econômica de regiões implica na geração de vantagens competitivas a esses territórios, que conseguem empreender atividades econômicas de modo integrado, com o compartilhamento de infraestruturas básicas, além de ampliar a difusão de ideias, hábitos e cultura, em uma conjuntura caracterizada como um verdadeiro "caldeirão" cultural, social e econômico (OGBOR; EROMAFURU, 2018).

Entende-se que a proposta contemporânea de criação do chamado Corredor Bioceânico, como parte da Rota de Integração Latino-americana (Rila), que pretende interligar países que são membros plenos do Mercosul (nominalmente, o Brasil, Paraguai e Argentina) ao Chile, por intermédio da recuperação e/ou construção de rodovias e ferrovias, tem como escopo fundamental possibilitar maior competitividade econômica aos territórios da América do Sul, além de catalisar o processo de transposição das barreiras físicas e culturais que eventualmente isolem os países sul-americanos signatários da proposta (RADDATZ; BUSS, 2014).

Constam nos objetivos do Corredor Bioceânico as seguintes particularidades (BNDES, 2010): (a) estímulo a maiores e melhores parcerias, sobretudo em termos econômicos, entre os países sul-americanos; (b) fomento ao intercâmbio cultural e de pessoas entre os territórios contemplados pela Rota, não raro por intermédio da difusão das práticas de turismo; (c) ampliação dos investimentos em equipamentos de infraestrutura de comunicação e transportes entre os países e; (d) diversificação das possibilidades de escoamento dos bens e serviços produzidos, sobretudo pelo Brasil, Argentina e Paraguai, para os mercados asiáticos, por intermédio dos portos chilenos.

O estado de Mato Grosso do Sul, em específico, tende a catalisar as suas dinâmicas de desenvolvimento com a efetivação do Corredor Bioceânico, principalmente porque, além de fazer fronteira com países da América do Sul, também concentrará uma série de investimentos, servindo de ponto de partida do Corredor, que se iniciará em Campo Grande, passando por outras cidades brasileiras, paraguaias, argentinas e chilenas, terminando nos portos das cidades de Iquique, Antofagasta e Mejillones, todas elas no norte do Chile (MATO GROSSO DO SUL, 2016). Acredita-se, portanto, que o território sul-mato-grossense será sobremaneira impactado com a criação e difusão, ao longo do Corredor Bioceânico, de uma série de atividades socioeconômicas - dentre as quais o próprio turismo (OLIVEIRA, 2010).

De uma maneira geral, destaque-se que o turismo perfaz um fenômeno social importante, caracterizado pelo constante deslocamento de pessoas, bens e serviços, sendo responsável pela geração de montantes significativos de emprego e renda para os territórios - no ano de 2017, as atividades características do turismo responderam pela geração de mais de US\$ 8,2 trilhões em todo o mundo, com expectativas de crescimento de 3,8\% desse montante, ao longo do ano de 2018 (WTTC, 2018; TUNG et al., 2017).

Na medida em que o Corredor Bioceânico se difundir e caminhar rumo à consecução de seus objetivos, o montante de pessoas ávidas por conhecer os atrativos turísticos dos territórios que o compõem aumentará, numa dinâmica que certamente implicará em benefícios socioeconômicos aos territórios turísticos sul-mato-grossenses, tais como o município de Bonito, MS, que está na área de influência da Rota e concentra um conjunto expressivo de atrativos turísticos relacionados à prática do ecoturismo (RÜCKERT; FILHO; UEBEL, 2015).

Sabe-se que os países signatários do Corredor Bioceânico se configuram como importantes emissores de turistas para Bonito. No ano de 2017, as nacionalidades da maioria dos turistas que visitaram a Gruta do Lago Azul (o mais importante atrativo turístico de Bonito) eram paraguaia e argentina. Esses países foram responsáveis por 1,46\% e 1,22\%, respectivamente, do total de 
turistas, sejam nacionais ou internacionais, que visitaram os atrativos turísticos do território sob análise, em 2017 (OTEB, 2017).

De todo modo, como os turistas provenientes dos países sul-americanos signatários do Corredor Bioceânico (Paraguai, Argentina e Chile) "enxergam" os detalhes dos atributos dos atrativos turísticos da cidade de Bonito, MS?

Com base no supracitado problema de pesquisa, o presente artigo tem como objetivo geral compreender os detalhes acerca dos atributos valorizados pelos turistas paraguaios, argentinos e chilenos que teceram comentários, na página online do TripAdvisor, sobre os atrativos turísticos visitados na cidade de Bonito, no Mato Grosso do Sul.

Deve-se ponderar, por ser oportuno, que o foco do presente estudo nos comentários postados na página do TripAdvisor deve-se ao fato de que é cada vez mais comum, por parte dos turistas que já visitaram um determinado atrativo turístico, o hábito de redigir impressões sobre suas experiências e postá-las na internet, principalmente com o propósito de auxiliar outros turistas em seus processos de tomada de decisão (BRANDT; BENDLER; NEUMANN, 2017). Por outro lado, o visitante que não conhece um determinado atrativo normalmente vale-se dos comentários e impressões, disponibilizadas na internet, como "pistas" para que consigam antever, com alguma segurança, os detalhes que cercam a sua prática turística (JACOBSEN; MUNAR, 2012). Assim sendo, percebe-se que é um expediente salutar monitorar os comentários e percepções postados na web, uma vez que, a partir dessas informações, é possível que se tenha um panorama da configuração geral da atividade turística em um determinado território, com o claro propósito de se ter subsídios para o incremento do turismo no contexto territorial que esteja sob análise.

Vale registrar ainda que a página on-line do TripAdvisor, além de se posicionar como um dos mais relevantes portais da internet para a interação entre turistas e organizações do setor de turismo e hotelaria, possui mais de 600 milhões de avaliações e comentários redigidos por turistas, que conseguem "conhecer" detalhes dos atributos de quase 8 milhões de equipamentos de apoio ao turismo (tais como acomodações, companhias aéreas e restaurantes), numa dinâmica em que os visitantes que navegam pelo site em análise passam dos 456 milhões, por mês (TRIPADVISOR, 2018).

Portanto, entende-se que os esforços analíticos em torno do presente artigo vão no sentido de, a partir do monitoramento dos comentários e impressões gerais, na página on-line do TripAdvisor, de turistas paraguaios, argentinos e chilenos, compreender o modo como esse perfil de turistas "vê" os atrativos turísticos de Bonito, MS, numa dinâmica em que, com base na sistematização das percepções do perfil de turistas investigado neste estudo, é possível que se tenham elementos para incrementar, por intermédio de políticas públicas e de negócios, os potenciais benefícios socioeconômicos e culturais do turismo no Mato Grosso do Sul, mais especificamente, e em todos os territórios que compõem o Corredor Bioceânico, de um modo geral. Destaque-se ainda que o presente artigo explora o "recorte empírico" Corredor Bioceânico, que ainda é algo muito emergente na literatura acadêmica especializada e, portanto, carece de maiores esforços analíticos para que sejam desnudados os bônus e eventuais desafios inerentes à consolidação da Rota. 


\section{O CORREDOR BIOCEÂNICO E O POTENCIAL DO TURISMO}

Pouco conhecido entre brasileiros e, mais especificamente, entre sul-mato-grossenses, o Corredor Bioceânico terá, no final, $2.396 \mathrm{~km}$ de percurso rodoviário, cujo início é na capital do Mato Grosso do Sul, passando por diversos territórios do Paraguai, Argentina e Chile, conforme ilustra a Figura 1.

Figura 1 - Mapa que indica os territórios contemplados pela Rota Bioceânica

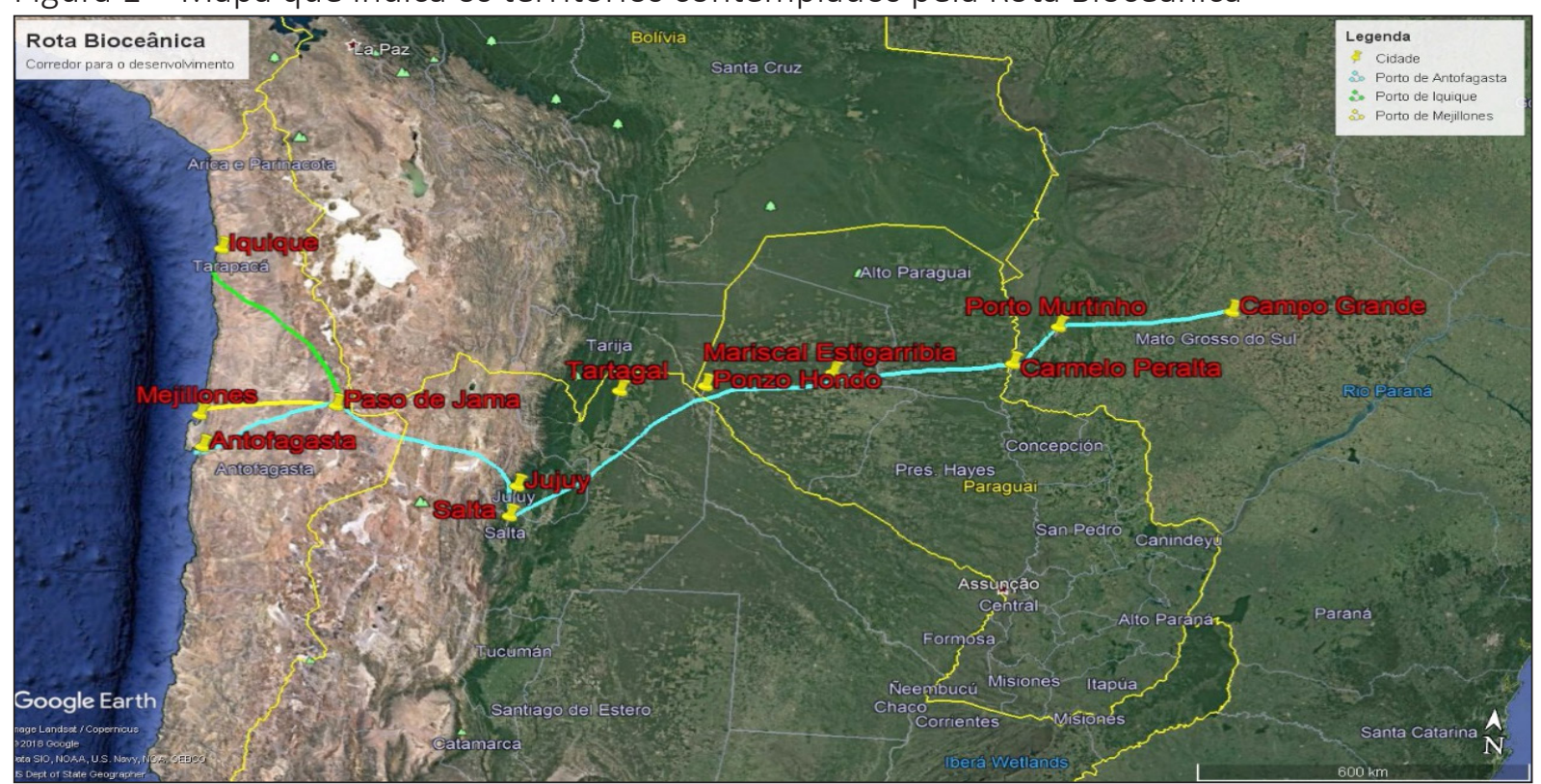

Fonte: Elaborado pelos autores, por intermédio do Google Earth.

O Corredor Bioceânico já foi "desbravado" em sua completude por duas expedições, em 2013 e 2017, capitaneadas por um grupo de empresários e gestores públicos. De todo modo, deve-se destacar que isso não significa que o Corredor represente um projeto pronto e consolidado: seu principal desafio é a construção de uma ponte sobre o Rio Paraguai, ligando o município brasileiro de Porto Murtinho ao território paraguaio de Carmelo Peralta, que estimada em R\$ 140 milhões, terá seu custo dividido pelos dois países (Paraguai e Brasil). Atualmente, a travessia, na região, é feita por pequenas embarcações, que levam um número limitado de veículos, de tal modo que sobre tais embarcações não passam veículos de carga (MATO GROSSO DO SUL, 2016).

A despeito dos dilemas e dos desafios, deve-se ressaltar que o Corredor Bioceânico possui um conjunto de potencialidades, sobretudo de ordem socioeconômica e cultural. Nessa acepção, entende-se que a atividade do turismo poderá ser uma relevante "mola propulsora" dos pontos positivos inerentes ao Corredor.

A Federação das Indústrias de Mato Grosso do Sul (FIEMS, 2013), ao reconhecer a importância do turismo e posicioná-lo como uma atividade estratégica e geradora de emprego, renda e difusão da cultura dos habitantes do território, elaborou um plano de ação que contempla as seguintes medidas:

- Realizar investimentos estruturais que desenvolvam roteiros de ecoturismo que combinem e integrem, em uma mesma "oferta de produto turístico", o Pantanal e Bonito (destinos já consagrados, no Mato Grosso do Sul e no Brasil), o Chaco paraguaio, a Cordilheira dos Andes, o deserto do Atacama e o litoral do Pacífico; 
- Desenvolver e integrar os serviços de recepção turística e intercâmbio cultural, entre os territórios contemplados pelo Corredor Bioceânico;

- Estimular voos de abrangência regional, facilitando a mobilidade de turistas entre os territórios que corporificam a Rota.

É importante considerar que, na área de influência do Corredor Bioceânico, residem mais de 5,5 milhões de pessoas, que poderão desenvolver o seu território por intermédio de atividades direta ou indiretamente ligadas ao turismo. Além disso, vale ponderar ainda que a supracitada população absoluta constitui relevante "público consumidor" de produtos direta ou indiretamente ligados ao turismo no âmbito do Corredor Bioceânico.

Dentre os vários atrativos turísticos que podem ser encontrados ao longo do trajeto do Corredor Rodoviário Bioceânico, destacam-se (a) o Pantanal sul-mato-grossense, no entorno do município de Porto Murtinho; (b) o Chaco paraguaio; (c) a Cordilheira dos Andes, na porção localizada em territórios argentinos e chilenos; (d) as praias da costa chilena, margeadas pelo Oceano Pacífico; (e) a rica gastronomia da região, com pratos típicos peculiares (tais como a Sopa Paraguaia - só para citar um exemplo emblemático); e (f) a cultura singular do território, que envolve o contato com povos e países de colonização portuguesa e espanhola, na América do Sul.

O município sul-mato-grossense de Bonito, foco específico das reflexões do presente estudo, a despeito de não ser um "ponto focal" do Corredor Bioceânico, está em sua área de influência, distante 100 quilômetros de Porto Murtinho (este sim, um ponto focal do Corredor).

Deve-se destacar que Bonito já se afigura, contemporaneamente, como um relevante destino turístico do Centro-Oeste brasileiro e do Mato Grosso do Sul, com um conjunto de atrativos ligados sobretudo às atividades de ecoturismo. Dentre os atrativos turístico de Bonito pode-se sublinhar passeios e visitas em grutas, cachoeiras, prática de arvorismo, boia-cross, cicloturismo, além de atividades de flutuação e mergulho em rios de águas cristalinas.

Acredita-se, em suma, que o território de Bonito pode posicionar-se como um relevante "chamariz" do Corredor Bioceânico, conclamando os próprios moradores do entorno do Corredor Rodoviário (brasileiros, paraguaios, argentinos e chilenos), assim como turistas provenientes de outras partes do mundo, a conhecerem os atrativos turísticos, tanto do território sob análise, quanto das demais localidades direta ou indiretamente sob influência do Corredor.

No tópico que segue há, portanto, uma tentativa de se explorar os atributos valorizados pelos consumidores de atrativos turísticos, com destaque para os estudos que analisaram as percepções e avaliações de turistas postadas na internet.

\section{ATRIBUTOS DOS ATRATIVOS TURÍSTICOS}

O atrativo turístico integra a oferta turística de um determinado destino e representa o fator que majoritariamente atrai visitantes para longe do seu habitat, numa dinâmica em que os atrativos podem ser construídos (um monumento, edificação ou parque de diversões, por exemplo) ou naturais (estes últimos normalmente ligados à natureza e, portanto, à ocorrência da prática turística em ambientes naturais) (HU; WALL, 2005).

O objetivo fundamental dos atrativos turísticos é proporcionar entretenimento e lazer, ou seja, tem-se como escopo fazer com que o turista disponha de parte de seu tempo para realizar atividades diferentes em relação àquelas desempenhadas rotineiramente, estimulando o universo hedônico das percepções do turista (DUMAZEDIER; 2013; MANOSSO et al., 2015; BOTTI; PEYPOCH; SOLONANDRASANA, 2008). 
Em suma, Mondo e Fiates (2016) identificaram os atributos de qualidade que mais são recorrentes nos comentários e análises de turistas em oito destinos brasileiros. O trabalho no campo netnográfico, conduzido pelos supracitados autores, elencou como os principais aspectos comentados pelos turistas: a) localização e acesso, que permitam deslocamentos rápidos e práticos; b) estética e infraestrutura - que condizem com os aspectos físicos, tanto naturais, quanto construídos ; c) segurança, inclui-se aí tanto a segurança do atrativo em si quanto da cidade ou região que o cerca; d) custo-benefício, ou seja: se o valor cobrado condiz com todos os aspectos de localização, estética e infraestrutura, segurança e atendimento; e) condições climáticas, atributo muito quisto principalmente nos atrativos que envolvem a natureza; e f) atendimento ao cliente - avaliam a presteza, polidez e educação dos colaboradores com os quais os turistas interagiram.

Mustelier-Puig, Anjum e Ming (2018) tiveram como objeto de estudo a relação entre a qualidade da interação com os serviços de atração turística e a satisfação. Os resultados sugerem o efeito direto entre a qualidade dessas interações com a satisfação e os serviços turísticos, afetando da mesma forma a satisfação geral do turista com o destino e na sua intenção de voltar. Dentro desta construção de interação virtuosa, os atributos que se destacaram foram - em ordem, segundo os supracitados autores foram a) o conhecimento do funcionário acerca de seu produto; b) atitude - inclui-se aí a educação, polidez e aspectos do atendimento; c) comportamento não-verbal, como a proatividade e prestatividade; e d) idioma, ainda que o não-verbal tenha se destacado, habilidades de se entender e fazer ser entendido oralmente também foram lembrados.

Já Anuar et al. (2014) investigam o conceito de destino turístico amigável, a partir de três dimensões, isto é, da atividade, do produto e do espaço - sendo produto o atrativo turístico em si. Quando isolada a dimensão produto, o estudo revela predicados que compõem um destino turístico amigável, ou seja, a) os recursos naturais - como cachoeiras, praias, vida selvagem e outros; b) serviço, que se bem empregado, é visto como extensão das características físicas, pois é necessário para desfrutá-las; c) liberdade de escolha - que pode ser traduzido como o poder de escolher o que fazer e quando fazer; d) hospitalidade - sentir-se acolhido naquele ambiente; e f) envolvimento, que agrega todos as atributos acima para que o turista participe ativamente da produção do produto turístico.

Em Mato Grosso do Sul, Mariani, Barboza e Arruda (2012), ao avaliarem o grau de satisfação dos turistas com o destino turístico de Jardim, município que integra o Parque Nacional da Serra da Bodoquena, apresentam atributos bem avaliados na opinião dos turistas, como hospitalidade, limpeza e higiene, além de cuidados ambientais (muito valorizado pelos turistas, que dão preferência a passeios ecológicos, ofertados em larga escala na localidade). De todo modo, há atributos com pontos que requerem melhorias, tais como: custos dos atrativos, aparato de saúde pública local e sinalização das atrações.

De uma maneira geral, pode-se depreender, a partir da revisão de literatura conduzida no presente artigo, que os turistas valorizam atributos relacionados à aspectos tangíveis dos atrativos turísticos (tais como beleza, layout e infraestrutura), ao atendimento, além da acessibilidade e da hospitalidade do local em que a atração está sediada.

De todo modo, os supracitados atributos aparecem nos comentários dos turistas de países que compõem o Corredor Rodoviário Bioceânico (nominalmente, paraguaios, argentinos e chilenos), em plataformas digitais - tais como o TripAdvisor -, quando se avaliam os detalhes das experiências em atrativos turísticos de Bonito, MS? No tópico que segue, apresentam-se os 
procedimentos metodológicos do presente estudo, em que se objetivou apresentar elementos que permitam uma reflexão em torno da supracitada pergunta.

\section{PROCEDIMENTOS METODOLÓGICOS}

O presente artigo apresenta uma abordagem qualitativa, em que foram utilizados princípios da netnografia para a coleta, sistematização e análise de informações disponibilizadas por turistas paraguaios, argentinos e chilenos na página on-line do TripAdvisor.

A netnografia perfaz um método qualitativo calcado em princípios da etnografia "clássica", muito útil para a coleta, sistematização e análise de dados disponíveis em ambientes on-line (POLIVANOV, 2013; FRAGOSO; RECUERO; AMARAL, 2011). Kozinets (2002, p. 62) esclarece que a netnografia representa "[...] uma nova metodologia de pesquisa qualitativa, que adapta técnicas de pesquisa da etnografia para estudar as culturas e comunidades que estão emergindo através de comunicações mediadas pelo computador".

Correia, Alperstedt e Feuerschutte (2017), além de Silva (2015), sinalizam que a netnografia (ou etnografia virtual) perfaz uma técnica de coleta e sistematização de dados muito útil contemporaneamente, sobretudo em função do fato de que as pessoas cada vez mais estabelecem interações em ambientes virtuais, numa dinâmica em que a compreensão e análise dos detalhes dessas interações on-line é um expediente crucial para que se consiga captar muitos elementos da percepção e comportamento dos indivíduos, inclusive no mundo real.

Kozinets (2010) pontua que há três tipos de dados (informações) que podem ser coletadas por intermédio do uso das lógicas inerentes à netnografia: (a) dados arquivais, que são aqueles que o pesquisador retira diretamente de comunicações pré-existentes, cuja criação ou estimulação não ficam a cargo dele [pesquisador]; (b) dados extraídos, que são aqueles que o pesquisador cria em conjunção com a comunidade online, através de interação pessoal e comunal e; (c) dados de notas de campo, que são as anotações que o próprio pesquisador registra de suas observações da comunidade, seus membros e a interação estabelecida.

Deve-se salientar que o presente estudo se baseou principalmente em dados arquivais conforme classificação de Kozinets (2010), acima descrita -, extraídos de comentários postados na página do TripAdvisor, no período de janeiro a dezembro de 2017, em espanhol, e identificados como sendo provenientes de turistas do Paraguai, Argentina e Chile (países esses signatários do Corredor Rodoviário Bioceânico), que visitaram Bonito e teceram comentários, no TripAdvisor, acerca dos atrativos que conheceram, no território sob análise no presente estudo. Deve-se salientar que, ao se extrair as informações da página do TripAdvisor, houve uma preocupação de se filtrar os comentários, com o propósito de que se contemplasse, neste estudo, somente as percepções de paraguaios, argentinos e chilenos quanto aos atrativos turísticos de Bonito.

Foram analisados, ao todo, 248 comentários em espanhol, que, a partir de uma organização prévia (preparação de um "corpus textual"), foram submetidos ao software Iramuteq, que processou os textos, realizou contagem da frequência absoluta de palavras, gerou imagens gráficas das palavras mais recorrentes nos comentários avaliados, além de sugerir palavras e termos mais fortemente relacionados uns com os outros, ao longo dos comentários dos turistas, na internet, na página do TripAdvisor.

O Iramuteq é um software gratuito e desenvolvido sob a lógica do opensource; ele ancora-se no ambiente do software estatístico $R$, e permite a realização de análises gerais de textos. Em 
resumo, por possuir uma interface com o software $\mathrm{R}$, o Iramuteq representa uma oportunidade para que sejam empreendidas formas de análises estatísticas de textos qualitativos, produzidos através de entrevistas em profundidade, relatórios e documentos diversos (SOUZA et al., 2018).

Deve-se ponderar que o uso de softwares - tais como o Iramuteq - na condução de pesquisas qualitativas e na análise de dados textuais é algo muito útil, sobretudo porque permite uma fácil organização e sistematização das informações, facilitando todo o processo de análises e discussões inerentes à pesquisa, a partir dos dados coletados (CAMARGO; JUSTO, 2013).

O Iramuteq é capaz de oferecer informações lexográficas, que também incluem estatísticas básicas, como frequência e quantidade de palavras; e outras funções mais avançadas, tais como: (a) a Análise Fatorial de Correspondência (AFC), que permite a elaboração de clusters de palavras mais fortemente correlacionadas; (b) a Classificação Hierárquica Descendente (CHD), que apresenta um teste de hipótese, a partir de uma probabilidade e de uma estatística qui-quadrado, quanto ao nível de correlação dos termos em determinados clusters (classes de palavras); (c) a Análise de similitude, que permite uma maior compreensão de como as palavras recorrentes são relacionadas com outras palavras, dentro do texto e; (e) a Nuvem de Palavras, que mostra, de forma gráfica, as palavras que mais se destacaram ao longo do corpus textual.

No âmbito do presente estudo, foram utilizados de modo recorrente três recursos do Iramuteq: a nuvem de palavras, análise de similitude e a Classificação Hierárquica Descendente (CHD), de tal modo que nesta última "técnica" os vocábulos são correlacionados, formando um esquema hierárquico de classes de palavras.

Registre-se, por ser oportuno, que o uso do software Iramuteq como ferramenta para a análise de dados textuais ainda é algo muito incipiente nas pesquisas no Brasil (CAMARGO; JUSTO, 2013). Muito embora o uso da supracitada ferramenta tenha obtido, desde 2013, uma ligeira relevância nos estudos da área da saúde pública brasileira, ressalte-se que ainda são embrionários os esforços do uso do Iramuteq nas pesquisas e reflexões na área do turismo e hospitalidade, especificamente - o que faz com que o presente artigo ganhe um caráter inédito e original.

Portanto, com base nos procedimentos acima delineados, foram feitas as principais constatações e inferências do estudo, conforme descrito no tópico que segue.

\section{RESULTADOS E DISCUSSÕES}

Após o processamento do software Iramuteq, o primeiro output a ser analisado é a nuvem de palavras (figura 2). Os termos lugar, ir, dar, ver e más foram omitidos da nuvem de palavras por não representarem por si só, neste gráfico, uma informação relevante. 
Figura 2 - Nuvem de palavras dos comentários extraídos da página do TripAdvisor

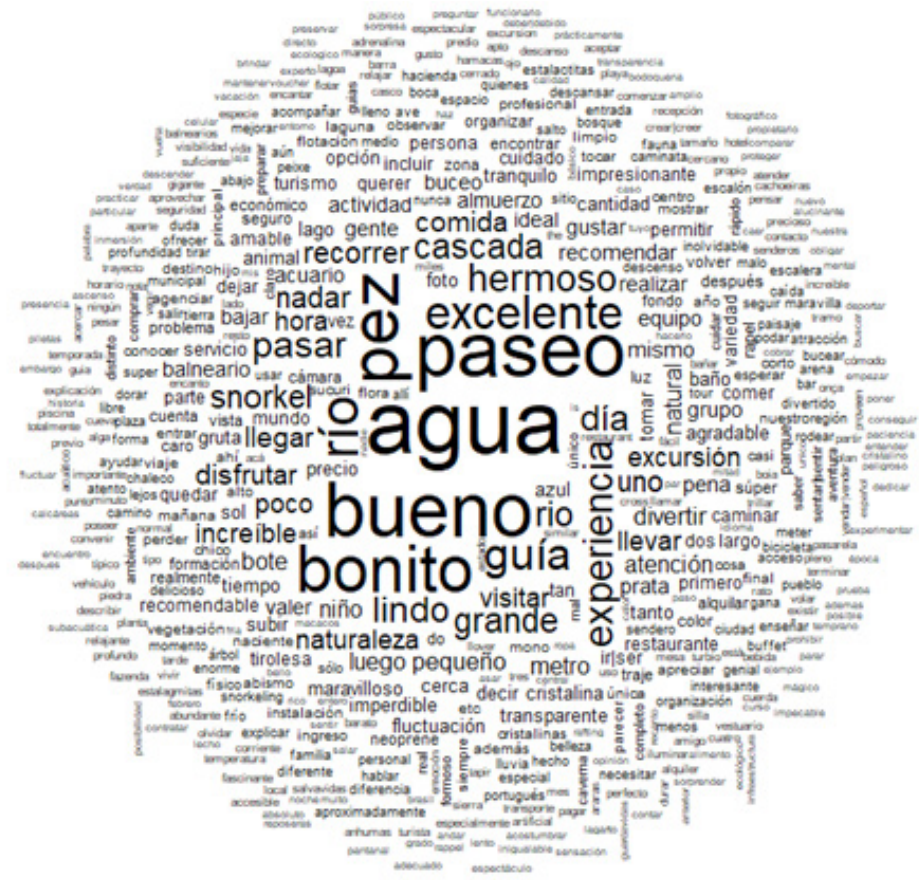

Fonte: Dados da pesquisa, processados com o uso do Iramuteq.

A nuvem de palavras tem como objetivo apresentar, de forma gráfica, as palavras que mais se destacaram dentro de um texto (comentários), onde as que foram mais repetidas estão no centro e em maior tamanho. Em uma primeira análise, fica evidente como as caraterísticas do ecoturismo reverberam nas falas dos turistas com agua, rio, pez, naturaleza e cascada. Todos esses termos robustecem a importância da natureza e da água como indutor da atividade turística do município de Bonito e como fonte da principal diversão desses visitantes. Outros destaques, paseo e excursión são recorrentes nas falas dos turistas, o que reforça a ideia de que o visitante que vai ao município de Bonito está interessado nas excursões que lá são oferecidas, remete a férias, recreação, onde as atividades não são apenas contemplativas, mas também participativas. Destaque para esse recorte de comentário:

El lugar es impresionante, el agua es muy cristalina, se ven muchos peces, 31 especies para ser exactos. Está prohibido usar productos sobre la piel, que puedan afectar la pureza del agua, no se puede usar repelente ni bloqueador solar, por ejemplo. El paseo cuenta con un pequeño bote de apoyo que acompaña al grupo durante el recorrido de unos 400 metros aproximadamente [...].

Com forte ocorrência estão também os adjetivos bueno, excelente, lindo e hermoso, enquanto Bonito, sem tradução para o espanhol, é uma referência à cidade. Orbitando no centro da nuvem, estão as palavras relacionadas a experiência, como nadar, snorkel, que é uma forma de mergulho em águas rasas que se assemelha muito com a flutuação, visitar e baño. Surpreende que a nuvem não tenha dado destaque aos aspectos do serviço, apenas guia em evidência pode evocar vagamente um atributo com esse fim, de forma mais discreta servicio aparece, como nesse comentário: "Excelente servicio, todas las personas son muy amables, hay muchas actividades para realizar, la que mas me gusto fue Boia Cross y la cabalgata".

A análise de similitude (Figura 3) permite uma maior compreensão de como as palavras recorrentes estão sendo relacionadas com outras dentro do texto. Para uma melhor visualização, aqui foram selecionadas apenas as palavras com mais de 20 menções totais nos comentários. 
Figura 3 - Análise de similitude das palavras dos comentários extraídos do TripAdvisor

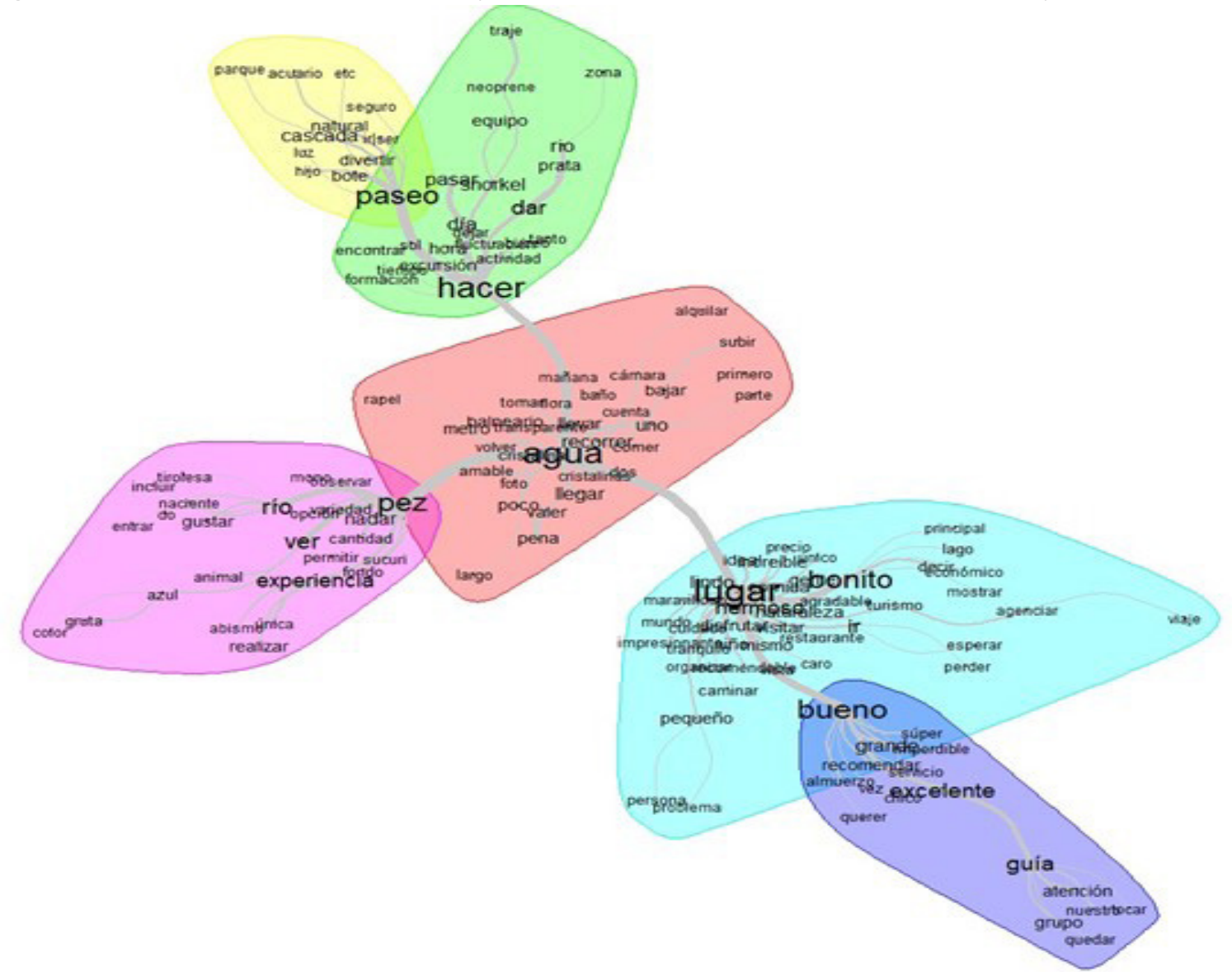

Fonte: Dados da pesquisa, processados com o uso do Iramuteq.

Com os clusters (essas formas geográficas de cores diferentes) é possível notar quais termos foram escritos, nos comentários analisados, conjuntamente e qual o grau de aproximação entre esses clusters (medido pela espessura da linha que os liga, quanto mais espesso, maior a proximidade). Em suma, paseo nos comentários está muito próximo de natural, cascada, bote, parque e outros que estão no universo dos passeios disponíveis na cidade. Com forte ligação está o verbo hacer que além de paseo também está no tocante às atividades turísticas do município como excursión, actividad e snorkel. Esse trecho coletado diretamente dos comentários ilustra essa situação: "[...] muy lindo lugar para pasar el día entero, los niños disfrutan el doble. hay areas de descanso bajo el hermoso y grandioso árbol da Figuera, podes hacer paseos y snorkel".

A água é a grande vedete de Bonito, perpassando praticamente todas as atrações do território. Nos comentários dos turistas chilenos, paraguaios e argentinos não poderia ser diferente. No centro da análise de similitude ela não é só a principal conectora, com todos os outros clusters, como também tem o seu próprio cluster recheado de elogios como cristalinas e transparente. De forma macroanalítica, é concebível captar sua importância, pois está diretamente com o que fazer (hacer) e com o lugar em si, além de peixes. Como diz um turista "[...] La vegetación, los peces, el fondo el río, la transparencia del agua inigualable. A mi marido y mi hijo fue el paseo que más les gustó".

O termo água é também o habitat do peixe, outro item que de tão encantador para os turistas, foi bastante mencionado, a ponto de ter seu próprio cluster. Uma atração à parte que 
motivou muito desses viajantes a contar como experiencia, única. A variedad de peixes e a possibilidade de nadar junto com esses animais foi um ponto que gerou enorme satisfação no cliente, e é retratado nessa revisão: "Una experiencia única, la de realizar este nado con los peces en el Rio da Prata, además el tour ya incluye un excelente almuerzo".

Fechando os dois últimos clusters, lugar e bueno trazem, respectivamente, detalhes gerais dos atrativos e elementos que os turistas consideraram bons. Nesse último, chama atenção que o guia foi destacado por um aspecto positivo atención, além do próprio bueno, como nesse contorno: "Muy buen lugar, cerca del centro, muy buena atención de la guia." Em lugar há muitos adjetivos diretamente relacionados, mas é possível encontrar fatores econômicos como precio, caro e económico. Como nenhum ganha particular notoriedade, não é possível extrair a partir do gráfico nenhuma conclusão sem recorrer a comentários, como: "El lugar es maravilloso. Único. Muy recomendable. Si desean hacer hay que contratar antes y con tiempo. Cupos limitados. Caro pero vale la pena." ou "Una opción económica !!!!! de todos los paseos disponibles es el más económico y no por ello menos interessante [...]".

Por fim, com base na AFC (Figura 4), é possível enxergar, dentro dos comentários, quais termos e palavras são ditas pelos grupos de turistas.

Figura 4 - Análise Fatorial de Correspondência (AFC) dos comentários do TripAdvisor

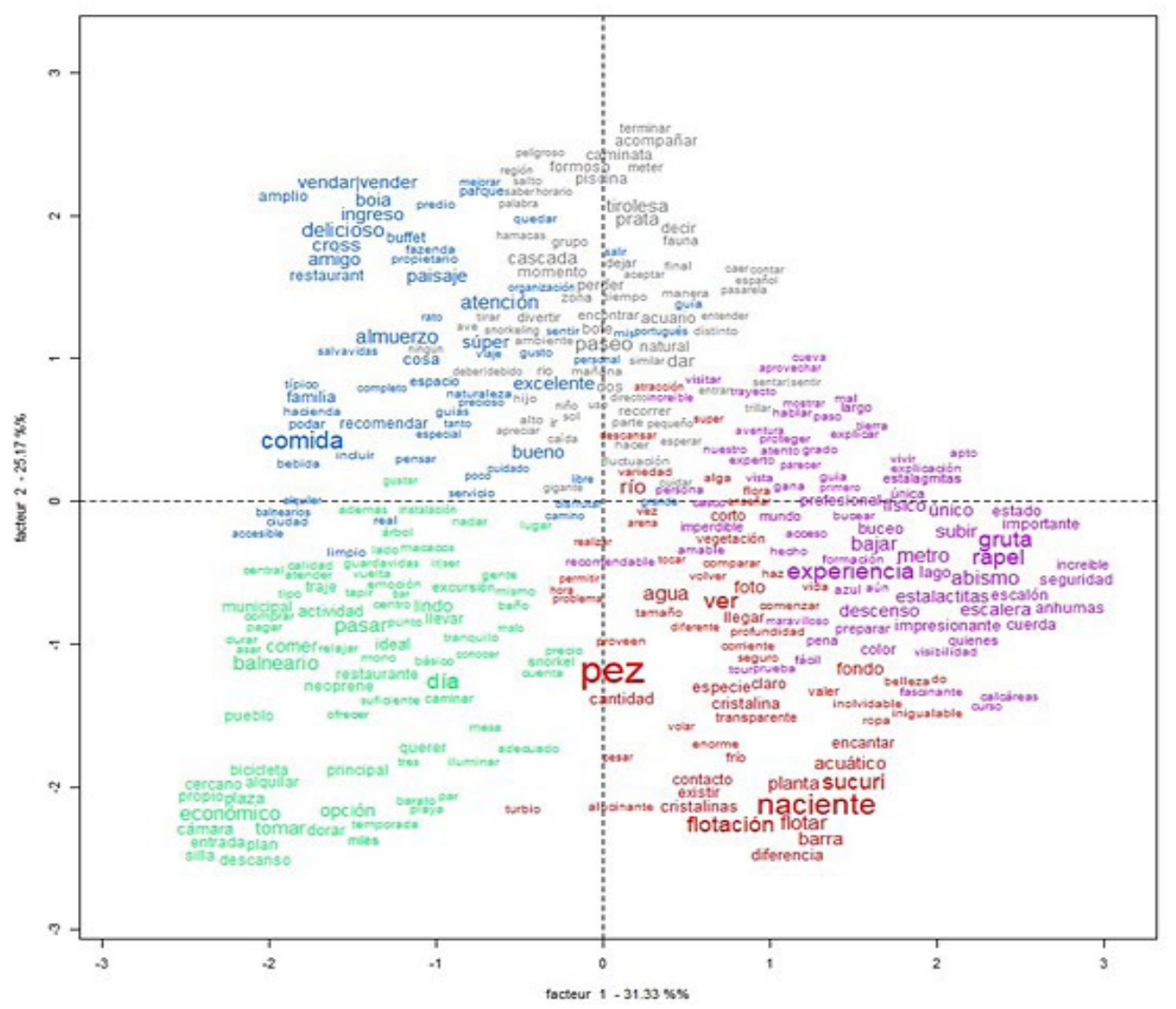

Fonte: Dados da pesquisa, processados com o uso do Iramuteq.

Os quatro quadrantes representam a distância de tais palavras dentro dos comentários, e ainda as cores criam pequenos subgrupos de termos, muito semelhantes com a análise de similitude, na figura 3. É palpável denotar as diferentes atrações do município de Bonito, a partir dos 
quadrantes. No inferior direito, estão aqueles fortemente ligados ao rio, onde o turista pode ter contato com peixes, fazer a flutuação e ter contato com o que a água pode oferecer de diversão. Ainda no quadrante direito, mas um pouco mais na região do meio e superior, estão atrações menos contemplativas e que exigem mais do turista, como indicam os termos rapel, reguridad, cuerda, subir e grut", que embora tenha como finalidade a apreciação, sempre vem acompanhada de trilhas que a guardam como uma espécie de recompensa pelo esforço. Este turista tece seu elogio e oferece sua dica no mesmo comentário: "Imperdible. Un lugar mágico. iUna gruta maravillosa! Solo requiere buen estado físico, pero aún sin él, los empleados se ocupan de ayudarte a subir. No apto para quienes temen a la altura. En pocos lugares del mundo se puede tener una experiencia como esta".

Do lado esquerdo superior, os atributos relacionados à estrutura de apoio dos atrativos como comida, servicio, organización e ingreso: "es un lugar muy agradable, tiene restaurant para comidas y bebidas, por lo que no permiten el ingreso de las mismas". No canto esquerdo inferior duas palavras ditam o quadrante, econômico e balneário, proveniente de turistas que contornaram os preços mais elevados dos atrativos mais famosos, recorrendo aos balneários que, embora com menos opções de divertimento, não deixam a desejar em água e, portanto, segundo os comentários dos turistas vizinhos, diversão.

Nota-se que nenhum dos gráficos deixou transparecer críticas aos atrativos de Bonito, o que não significa que não existam, mas são, de fato, em número bem menor que os positivos, sendo necessário separar os recortes para que sejam visualizados, como: "Nadie habla otro idioma que el Portugués, ni siquiera en la secretaría de Turismo que tiene un local en el ingreso a Bonito (está cerrado) y atienden en la Prefectura"; ou este turista que teve sua experiência estragada no final de sua viagem:

Todo muy bueno excepto el final. Al finalizar nos tuvieron 25 minutos esperando en una camioneta, cansados y con ganas de salir. Cuando preguntamos qué tan lejos era la Recepción para ir caminando nos dijeron $2 \mathrm{~km}$ cosa que nos parecía Extraña. Finalmente resultaron ser 600 metros. Muy mal educados. Eso nos arruinó la experiencia.

Ademais, a beleza natural de Bonito é inquestionável e os comentários mostram que, em geral, o destino está preparado para receber os novos visitantes que certamente virão com a consolidação do Corredor Rodoviário Bioceânico.

\section{CONSIDERAÇÕES FINAIS}

O presente artigo teve como propósito analisar, por intermédio de uma pesquisa qualitativa, com o uso de técnicas da netnografia, os detalhes em torno dos principais atributos valorizados por turistas do Paraguai, Argentina e Chile (países signatários da Rota Bioceânica), que teceram comentários, na página online do TripAdvisor, acerca de atrativos turísticos localizados no município de Bonito, MS, no Centro-Oeste brasileiro.

Ainda que o Corredor Rodoviário Bioceânico possa parecer um fruto natural da globalização, a crescente onda de governos protecionistas emergindo em países principalmente europeus, eleva a importância e a coragem daqueles que defenderam e ainda defendem a estruturação desse importante corredor de integração. Se o retorno comercial é garantido, pode-se dizer que o cultural e o turístico também, ainda que os habitantes dos três países que serão interligados ao Brasil já sejam "velhos conhecidos" no trade turístico de Bonito. 
Entende-se que as contribuições deste trabalho vão no sentido de sugerir um maior estreitamento das relações socioeconômicas e culturais, por intermédio do turismo, entre os países pelos quais passa o Corredor Rodoviário. Assim como nos países europeus, onde a distância reduzida e a facilidade de locomoção permitem que seus moradores trafeguem pelas mais variedades cidades e atrativos turísticos, o Corredor poderá integrar os povos sul-americanos, de modo que esse "caldo cultural" fique ainda mais denso, formando pessoas capazes de respeitar as tradições, sabedorias e particularidades de cada povo.

Não obstante, faz-se importante frisar outra contribuição pretendida pelos autores do presente trabalho: subsidiar profissionais da área do marketing a criar peças publicitárias com o foco nesse público-alvo. Os resultados do trabalho explicitam "chamarizes" que podem ser trabalhados no convencimento de trazer turistas até a cidade, desenvolvendo não só Bonito, como também o seu entorno, aumentando a área de influência do Corredor Rodoviário.

O turismo, desenvolvedor de uma região, tem as totais condições de ser aprimorado no município de Bonito com a consolidação do Corredor. Os turistas provenientes desses países não só encontrarão referências positivas de conterrâneos no TripAdvisor, como também encontrarão uma cidade já acostumada a recebê-los e que já tem know-how suficiente para conduzir esse processo todo da melhor forma.

Destaque-se que o uso do Iramuteq se mostrou uma ferramenta muita útil na sistematização das informações utilizadas no presente estudo. O software, ainda que subordinado a interpretações, reduz possíveis erros na execução da netnografia, por restringir a possibilidade de se enviesar os resultados e inferências decorrentes do estudo.

Os resultados, em síntese, corroboram a cidade como destino do ecoturismo, tendo a água como fonte principal de diversão dos turistas e várias atrações orbitando ao redor de sua presença, como a flutuação ou snorkel, cachoeiras, rios e peixes. Esses atributos, os mais observados e apreciados pelos viajantes paraguaios, argentinos e chilenos, responsabilizam Bonito a seguir uma ideia de turismo sustentável.

De modo geral, os visitantes apreciaram os recursos naturais que Bonito tem a oferecer, desferindo com eloquência elogios aos atrativos e, de maneira mais tímida, aos guias, a alimentação e aos serviços de apoio, tais como restaurantes.

Ainda sobre os resultados, os turistas chilenos, paraguaios e argentinos se mostraram bem econômicos nos atributos comentados no TripAdvisor. Ao contrário dos trabalhos de Mondo e Fiates (2016), Mustelier-Puig, Anjum e Ming (2018), Anuar et al. (2014), além de Mariani, Barboza e Arruda (2012), esse turista não se mostrou particularmente interessado por atributos como acesso e localização, atendimento ao cliente, hospitalidade, sinalizações e apoio de saúde.

Alguns atributos, por outro lado, se mostraram alinhados com os trabalhos supracitados. São eles: a estética; custo-benefício (ainda que em escala reduzida); idioma; recursos naturais e o envolvimento do turista com a atração.

Futuramente há de se pesquisar outros atores que compõem o trade turístico como hotéis, bares, restaurantes e agências de turismo, tanto sob a ótica desses turistas do Mercosul e do Chile em visita ao Brasil, quantos dos brasileiros quando usufruindo da infraestrutura e dos atrativos destes países. A limitação deste estudo se encontra na impossibilidade de assegurar os resultados como generalizados para os turistas que não utilizam as mídias sociais para exprimir seu contentamento ou angústia. 


\section{REFERÊNCIAS}

ANUAR, Ahmad; AHMAD, Habibah; JUSOH, Hamzah; HUSSAIN, Mohd Yusof. The formation of tourist friendly destination in Kuala Lumpur: a qualitative study of stakeholder perspectives. Advances in Natural and Applied Sciences, v. 8, n. 4, p. 213-23, 2014.

BANCO NACIONAL DE DESENVOLVIMENTO ECONÔMICO E SOCIAL (BNDES). Avaliação dos Corredores Bioceânicos. Rio de Janeiro: BNDES, 2010.

BOTTI, Laurent; PEYPOCH, Nicolas; SOLONANDRASANA, Bernardin. Time and tourism attraction. Tourism Management, v. 29, n. 3, p. 594-6, 2008.

BRANDT, Tobias; BENDLER, Johannes; NEUMANN, Dirk. Social media analytics and value creation in urban smart tourism ecosystems. Information \& Management, v. 54, n. 6, p. 703-13, 2017.

CAMARGO, Brigido Vizeu; JUSTO, Ana Maria. IRAMUTEQ: um software gratuito para análise de dados textuais. Revista Temas em Psicologia, Ribeirão Preto, v. 21, n. 2, p. 513-18, 2013.

CORREIA, Rafaela Rodrigues; ALPERSTEDT, Graziela Dias; FEUERSCHUTTE, Simone Ghisi. O Uso do Método Netnográfico na Pós-Graduação em Administração no Brasil. Revista de Ciências da Administração, v. 19, n. 47, p. 163-175, 2017.

D'ONOFRIO, Alexandra; ROUSSEAU, Peter. Financial Development, Trade Openness and Growth in the First Wave of Globalization. Comparative Economic Studies, v. 60, n. 1, p. 105-14, 2018.

DUMAZEDIER, Joffre. Sociologia empírica do lazer. São Paulo: Editora Perspectiva, 2013.

FEDERAÇÃO DAS INDÚSTRIAS DE MATO GROSSO DO SUL (FIEMS). Fiems destaca importância de Rota Bioceânica para a economia estadual. 2013. Disponível em: http://www.fiems.com.br/noticias/fiemsdestaca-importancia-de-rota-bioceanica-para-economia-estadual/16704. Acesso em: 30 out. 2018.

FRAGOSO, Suely; RECUERO, Raquel; AMARAL, Adriana. Métodos de pesquisa para internet. Porto Alegre: Sulina, 2011.

HU, Wei; WALL, Geoffrey. Environmental management, environmental image and the competitive tourist attraction. Journal of Sustainable Tourism, v. 13, n. 6, p. 617-35, 2005.

JACOBSEN, Jens Kr. Steen; MUNAR, Ana María. Tourist information search and destination choice in a digital age. Tourism Management Perspectives, v. 1, p. 39-47, 2012.

KOZINETS, Robert. Netnography: doing ethnographic research online. California: Sage Publications, 2010.

KOZINETS, Robert. The field behind the screen: using netnography for marketing research in online communities. Journal of Marketing Research, v. 39, n. 1, p. 61-72, 2002.

MANOSSO, Franciele; BIZINELLI, Camila; ABRAHÃO, Maria de Sena; GÂNDARA, José Manoel Gonçalves. Os atrativos turísticos de Curitiba-PR: uma perspectiva através do Guia Brasil Quatro Rodas. Revista Brasileira de Pesquisa em Turismo, São Paulo, v. 9, n. 1, p. 97-120, 2015.

MARIANI, Milton Augusto Pasquotto; BARBOZA, Mariana Monfort; ARRUDA, Dyego de Oliveira. Elementos determinantes de la satisfacción del consumidor de servicios turísticos. Estudios y Perspectivas en Turismo, Buenos Aires, v. 21, n. 5, p. 1244-61, 2012. 
MATO GROSSO DO SUL (Estado). Antecedentes - Seminário "Corredor Bioceânico Rodoviário". 2016. Disponível em: http://www.corredorbioceanico.ms.gov.br/antecedentes/. Acesso em: 24 out. 2018.

MONDO, Tiago Savi; FIATES, Gabriela. Atributos de la calidad de servicios en atractivos turisticos: un estudio netnográfico en el uso del protocolo TOURQUAL. Estudios y Perspectivas en Turismo, Buenos Aires, v. 25, n. 2, p. 124-142, 2016.

MUSTELIER-PUIG, Lilian Consuelo; ANJUM, Amna; MING, Xu. Interaction quality ans satisfaction: an empirical study of international tourists when buying Shanghai tourist attraction services. Cogent Business \& Management, v. 5, n. 1, p. 1-20, 2018.

OGBOR, John Oghenechuko; EROMAFURU, Edward. Regional trade blocs, location advantage and enterprise competitiveness in the global economy. Archives of Business Research, v. 6, n. 6, p. 11-27, 2018.

OLIVEIRA, Valquíria de Araújo. A infraestrutura de transportes como política governamental para o desenvolvimento regional e a integração sul-americana: uma análise sobre as Rotas Bioceânicas em Mato Grosso do Sul. 145f. Dissertação (Mestrado em Geografia) - Universidade Federal da Grande Dourados (UFGD), Dourados, MS, 2010.

OBSERVATÓRIO DO TURISMO E EVENTOS DE BONITO-MS (OTEB). Anuário estatístico do turismo de Bonito - Ano Base - 2017. Bonito, MS: OTEB, 2017.

POLIVANOV, Beatriz Brandão. Etnografia virtual, netnografia ou apenas etnografia? Implicações dos conceitos. Revista Esferas, Brasília-DF, v. 2, n. 3, p. 61-71, 2013.

RADDATZ, Lizandro; BUSS, Ricardo Niehues. Rota Bioceânica Norte como alternativa de escoamento de produção da soja pelo Oceano Pacífico. Revista Científica do ITPAC, Araguaína, v. 7, n. 4, p. 1-10, 2014.

RÜCKERT, Aldomar; CARNEIRO FILHO, Camilo; UEBEL, Roberto. Cenários de Transfronteirizações na América do Sul: alguns exemplos de pesquisas recentes. Revista GeoPantanal, Corumbá, v. 10, n. 18, p. 159-81, 2015.

SILVA, Suelen de Aguiar. Desvelando a Netnografia: um guia teórico e prático. Intercom - Revista Brasileira de Ciências da Comunicação, São Paulo, v. 38, n. 2, p. 339-42, 2015.

SOUZA, Marli; WALL, Marilene; THULER, Andrea; LOWEN, Ingrid; PERES, Aida. O uso do software IRAMUTEQ na análise de dados em pesquisas qualitativas. Revista da Escola de Enfermagem da USP, São Paulo, v. 52, p. 1-7, 2018.

TRIPADVISOR. Sobre o TripAdvisor. [S.d.]. Disponível em: https://tripadvisor.mediaroom.com. Acesso em: 8 set. 2018.

TUNG, Vincent Wing Sun; LIN, Pearl; ZHANG; Hanqin Qiu; ZHAO, Aimin. A framework of memory management and tourism experiences. Journal of Travel \& Tourism Marketing, v. 34, n. 7, p. 853-66, 2017.

WORDL TRAVEL AND TOURISM COUNCIL (WTTC). Travel \& Tourism - Economic Impact 2018 - World. United Kingdom: WTTC, 2018.

\section{Sobre autores:}

Maurílio Barbosa de Oliveira da Silva - Mestrando em Administração pela Escola de Administração e Negócios da Universidade Federal de Mato Grosso do Sul (ESAN/UFMS). 
Tecnólogo em Processos Gerenciais pela UFMS. E-mail: barbosamaurilio@hotmail.com, Orcid: http://orcid.org/0000-0002-8498-3010

Maria Clara de Souza Moreira - Pós-Graduanda em Gestão Pública, e Tecnóloga em Processos Gerenciais pela Universidade Federal de Mato Grosso do Sul (UFMS). E-mail: mariaclaramoreira_@hotmail.com, Orcid: http://orcid.org/0000-0002-5173-9062

Dyego de Oliveira Arruda - Pós-Doutorando junto ao Programa de Pós-Graduação em Administração da Universidade Federal de Mato Grosso do Sul (UFMS). Doutor em Administração de Organizações pela Universidade de São Paulo (USP). Professor do Centro Federal de Educação Tecnológica Celso Suckow da Fonseca (CEFET-RJ). Orientador no Mestrado em Relações Étnico-Raciais (PPRER), do CEFET/RJ. E-mail: dyego.arruda@gmail.com, Orcid: http://orcid.org/0000-0002-9514-284X

Milton Augusto Pasquotto Mariani - Doutor em Geografia Humana pela Universidade de São Paulo (USP). Professor efetivo da Universidade Federal de Mato Grosso do Sul (UFMS). Orientador nos programas de Mestrado e Doutorado Acadêmico em Administração, e no Programa de Mestrado Profissional em Estudos Fronteiriços, ambos pela Universidade Federal de Mato Grosso do Sul (UFMS). E-mail: miltmari@terra.com.br, Orcid: http://orcid.org/0000-0001-9485-0150 